\title{
Discovertebral (Andersson) lesions in severe ankylosing spondylitis: a study using MRI and conventional radiography
}

\author{
Mirjam K. de Vries • Anne S. van Drumpt • \\ Barend J. van Royen • J. Christiaan van Denderen • \\ Radu A. Manoliu • Irene E. van der Horst-Bruinsma
}

Received: 17 November 2009 /Revised: 13 April 2010 /Accepted: 29 April 2010 / Published online: 23 May 2010

(C) The Author(s) 2010. This article is published with open access at Springerlink.com

\begin{abstract}
The objective of this study is to investigate the prevalence of Andersson lesions (AL) in ankylosing spondylitis (AS) patients who will start anti-tumor necrosis factor (TNF) treatment. Radiographs and magnetic resonance imaging (MRI) of the spine were performed before therapy with anti-TNF. ALs were defined as discovertebral endplate destructions on MRI, associated with bone marrow edema and fat replacement or sclerosis, a decreased signal on $\mathrm{T} 1$, enhancement after contrast administration (gadolinium diethylenetriamine pentaacetic acid (Gd-DTPA)), and increased signal on T2 and short tau inversion recovery (STIR). Additionally, conventional radiography showed a fracture line, irregular endplates, and increased sclerosis of adjacent vertebral bodies. Fifty-six AS patients were included, 68\% males, mean age of 43 years, and mean disease duration of 11 years. The mean bath ankylosing
\end{abstract}

Source of support This investigation was facilitated by the Clinical Research Office of the Jan van Breemen Institute, which receives financial support from the Dutch Arthritis Foundation.

M. K. de Vries · I. E. van der Horst-Bruinsma $(\bowtie)$ Department of Rheumatology, VU University Medical Center, Room 3A-64, P.O. Box 7057, 1007 MB Amsterdam,

The Netherlands

e-mail: IE.vanderhorst@vumc.nl

A. S. van Drumpt • B. J. van Royen

Department of Orthopaedic Surgery, VU University Medical Center,

Amsterdam, The Netherlands

\section{R. A. Manoliu}

Department of Radiology, VU University Medical Center, Amsterdam, The Netherlands

J. C. van Denderen

Department of Rheumatology, Jan van Breemen Institute,

Amsterdam, The Netherlands spondylitis disease activity index was 6.4 , and $24 \%$ of all patients had ankylosis. Only one patient showed a discovertebral abnormality with bone marrow edema of more than $50 \%$ of the vertebral bodies adjacent to the intervertebral disk of T7/T8 and T9/T10, a hypodense signal area on T1, and a high signal on STIR. Irregular endplates were depicted, and T1 after Gd-DTPA demonstrated high signal intensity around the disk margins. However, no fracture line was visible on conventional radiology, and therefore, this case was not considered to be an AL. No AL was detected in our AS patients, who were candidates for antiTNF treatment. One patient showed a discovertebral abnormality on MRI, without a fracture line on conventional radiology. The relative small proportion of patients with a long-established disease might explain this finding for, particularly, an ankylosed spine is prone to develop an AL.

Keywords Andersson lesion - Ankylosing spondylitis . anti-TNF. Discovertebral lesion $\cdot$ MR imaging

\section{Introduction}

Ankylosing spondylitis (AS) is a chronic inflammatory rheumatic disease that affects especially males in the second and third decades of life, with a prevalence of $0.5-0.9 \%$ [1]. The main clinical symptom is inflammatory back pain typically occurring at night and morning stiffness improving after exercise. The pain, stiffness, and limited mobility of the spine can cause severe limitations in daily life activities.

Inflammation in AS usually is localized in the sacroiliac joints and the axial skeleton. The last decade there is an increasing interest in the spinal involvement in AS visible on magnetic resonance imaging (MRI) [2-5]. There is a wide range of abnormalities described in the spine of AS 
patients. Apart from syndesmophytes and ankylosis of the spine resulting in rigidity, in longstanding AS, also focal destructive discovertebral lesions (Andersson lesion (AL)) can occur, also known as ALs [6, 7]. In 1996, Rasker et al. described six cases of spondylodiscitis in AS [8].

Recently, we described a review on ALs, which show disk space narrowing or widening, vertebral bone destruction, a surrounding zone of sclerosis, and local kyphosis at radiographs of the spine (Fig. 1) [7]. One of the causes of an AL is the local inflammation in the spine in combination with a minor trauma. This lesion can be differentiated from the signs of inflammation at the MRI of the spine of active disease in AS, as is often observed in patients who are candidates for tumor necrosis factor (TNF) blocking treatment. An AL might be difficult to detect on clinical symptoms alone because most AS patients suffer from back pain. More important is the fact that an $\mathrm{AL}$ requires a different treatment, for instance immobilization, in contrast with the physical therapy normally prescribed in AS patients.

The aim of this study was to investigate whether in AS patients, who are candidates for treatment with anti-TNF, ALs could be detected.

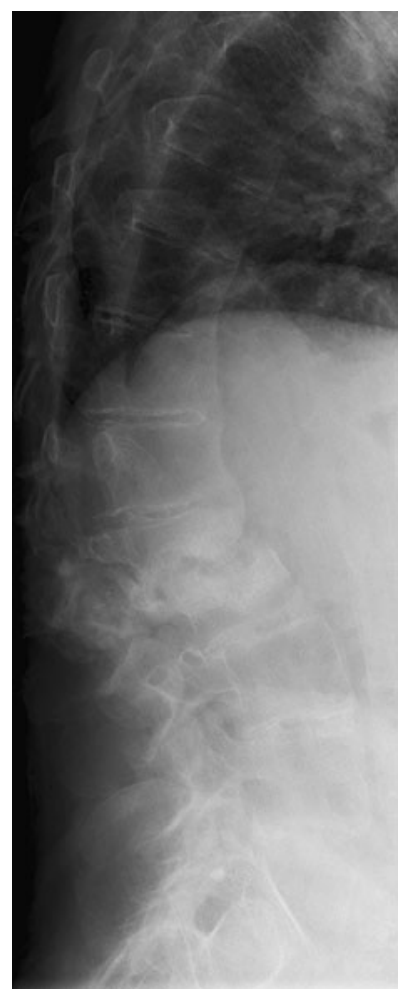

Fig. 1 A lateral radiograph of the lumbar spine shows an Andersson lesion with extensive bony destruction of the L1-L2 disk with irregular endplates and increased sclerosis of adjacent vertebral bodies (from Van Royen et al. with permission)

\section{Methods}

\section{Patients}

AS patients were derived from the outpatient clinics of the VU University Medical Center (Vumc) and the Jan van Breemen Institute (JBI) in Amsterdam. All AS patients who fulfilled the modified New York criteria and met the criteria for starting treatment with TNF-blocking agents according to the international ASAS consensus statement [9, 10] were included.

Following this ASAS statement, all patients had an active disease as defined by a bath ankylosing spondylitis disease activity index (BASDAI) of $\geq 4$ (scale 0-10) [11], had failed to previous therapy with at least two nonsteroidal anti-inflammatory drugs and sulfasalazine in case of peripheral arthritis, and should be treated with TNFblocking agents according to an expert. Patients were enrolled consecutively, but mainly because of limited availability of the MR scanner, several patients could not be included. Furthermore, one patient did not fit into the scanner due to severe kyphosis, and several patients suffered from claustrophobia. At baseline, data that conform to daily clinical practice during treatment with TNFblocking agents were collected in all patients who gave their written informed consent.

\section{Radiology}

Standing anteroposterior and lateral full-length plain films and an MRI of the whole spine were performed before the start of anti-TNF therapy. MRI were obtained at baseline and after 6-24 months of anti-TNF therapy, using T1weighted spin-echo sequences (T1) before and after administration of the contrast medium gadolinium diethylenetriamine pentaacetic acid (Gd-DTPA), T2-weighted sequences (T2), and fat-suppression sequences (short tau inversion recovery (STIR)). In patients included in the JBI, MRI of the spine was performed in the Amstelland Hospital Amstelveen with a field strength of 0.5 tesla, starting from the third cervical vertebra (C3) and downwards. In patients included in the Vumc, MRI of the whole spine was performed with a field strength of 1.5 tesla. Pre- and post(Gd) T1 TSE and STIR MRIs were acquired. In the Amstelland Hospital Amstelveen, T2 was acquired as well.

The conventional radiographs and MRI were read by two observers, one orthopedic surgeon (BvR) and a radiologist $(\mathrm{RM})$, who were blinded to the status of the subjects. The consensus score was accepted. First, the conventional radiographs were analyzed followed by an assessment of the MRI. The extent of spinal ankylosis in the total study cohort was estimated by counting extensive syndesmophyte formation or bamboo spine features on conventional radiographs counted by segment. 
The extent of abnormalities in the discovertebral unit was compared with the same discovertebral unit in different sagittal MR sequences and the other way around.

An AL was defined as an abnormality in the discovertebral junction that shows on MRI diffuse endplate destruction, with associated bone marrow edema and fat replacement or sclerosis [12]. The fracture cleft through the disk space or vertebra itself is depicted as decreased signal on T1 and increased signal on T2, STIR, and T1 imaging after Gd-DTPA administration, reflecting reactive edema of the fracture. Conventional radiography of the $\mathrm{AL}$ must show a fracture line, irregular endplates, and increased sclerosis of adjacent vertebral bodies.

\section{Statistical analysis}

This concerns a descriptive study. Continuous variables were reported as the mean $\pm \mathrm{SD}$ or, if skewed, as the median (range). Categorical variables were calculated as frequencies and percentages.

\section{Results}

In total, 56 AS patients were included, 36 in the VUmc and 20 in the JBI, and the baseline characteristics of all patients are summarized in Table 1. Patients from the two centers did not differ in gender, age, or disease activity at baseline. Radiographs at baseline were available in 55 of the total 56 patients. MRI was performed at baseline in all 56 patients. In two patients, an alternative MRI procedure was performed due to a severe kyphotic posture. These MR scans were still suitable for the purpose of our study.

\section{Radiology}

Systematic examination of conventional radiographs of the cervical, thoracic, and lumbar spine did not reveal any lesions that met the definition of AL. Distinct ankylosis with extensive syndesmophyte formation was seen in 13 of 55 (24\%) of the patients determined with conventional radiography of the spine. Spinal ankylosis or bridging syndesmophytes over multiple vertebrae were seen at the cervical, thoracic, and lumbar segment in $16 \%, 6 \%$, and $7 \%$ of patients, respectively.

Conventional radiographs and MRIs of the whole spine showed no AL according to our definition. However, one patient showed a discovertebral abnormality on MRI. This abnormality showed bone marrow edema of more than $50 \%$ of the vertebral bodies adjacent to the intervertebral disk of T7/T8 and T9/T10 (Fig. 2), a hypodense signal area on T1 and high signal on STIR. Irregular endplates of the vertebra at these levels were depicted on all sequences. T1 after administration of Gd-DTPA demonstrated high signal intensity around the disk margins of T7/T8 and T9/T10. However, no fracture line was visible on conventional radiology.

The clinical characteristics of this patient did not differ from the other patients. He was a male, aged 65 years, with a BASDAI and CRP of 5 and $35 \mathrm{mg} / \mathrm{L}$, respectively, indicative of an active disease. He did not report any specific localizing complaints or a preceding (minor) trauma. He had suffered from complaints of low back pain for 40 years and was diagnosed with AS at the age of 51 .

After 24 months treatment with infliximab, T1weighted images showed a decrease of signs of acute inflammation such as bone marrow edema and maybe even an increase of post-inflammatory fatty bone marrow degeneration around the disk margins. The T1-weighted post-contrast images demonstrated no high signal intensity around the disk margins of T7/T8 and T9/T10 anymore. There were signs of progression of the ankylosis and kyphosis in the thoracic segment after 2 years of follow-up despite anti-TNF treatment. Apart from the focus on ALs, other abnormalities involving the discovertebral unit as described in literature on MRI in AS were encountered. Romanus lesions, which are acute inflammatory lesions at the corners of the endplates of
Table 1 Baseline characteristics

\footnotetext{
${ }^{a}$ Disease duration: mean time between the diagnosis and baseline

${ }^{\mathrm{b}}$ Symptom duration: mean time between the first symptoms and baseline

${ }^{\mathrm{c}}$ BASDAI: bath ankylosing spondylitis disease activity index; mean value, 11
}

\begin{tabular}{|c|c|c|}
\hline & Mean \pm SD & Range \\
\hline Number & 56 & \\
\hline Age (in years) & $43 \pm 10.8$ & $22-73$ \\
\hline Male gender $(\%)$ & 38 & 68 \\
\hline Disease duration (in years) ${ }^{\mathrm{a}}$ & $11 \pm 8.7$ & $1-41$ \\
\hline Symptom duration (in years) ${ }^{\mathrm{b}}$ & $21 \pm 11.3$ & $1-49$ \\
\hline BASDAI $(0-10)^{\mathrm{c}}$ & $6.4 \pm 1.4$ & $4.0-9.7$ \\
\hline Tragus-to-wall distance (cm; normal, $<15 \mathrm{~cm}$ ) & $16 \pm 6.0$ & $11-44$ \\
\hline Lumbar flexion index $(\mathrm{cm}$; normal, $>5 \mathrm{~cm})$ & $2.5 \pm 1.2$ & $0.3-5$ \\
\hline Lumbar side flexion (cm; normal, $>10 \mathrm{~cm}$ ) & $10 \pm 4.9$ & $3.8-19$ \\
\hline Chest expansion (cm; normal, $>5 \mathrm{~cm}$ ) & $3.4 \pm 1.5$ & $0.5-7$ \\
\hline
\end{tabular}


Fig. 2 a T1-weighted gadolinium diethylenetriamine pentaacetic acid postcontrast image demonstrated high-signal intensity around the disk margins of T7-T8 and T9-T10. b T1weighted image shows lowsignal intensity bone marrow edema in the adjacent vertebral endplates of the T7/T8 and T9/ T10 disk spaces. c T1-weighted image, obtained 24 months after treatment with anti-tumor necrosis factor agents
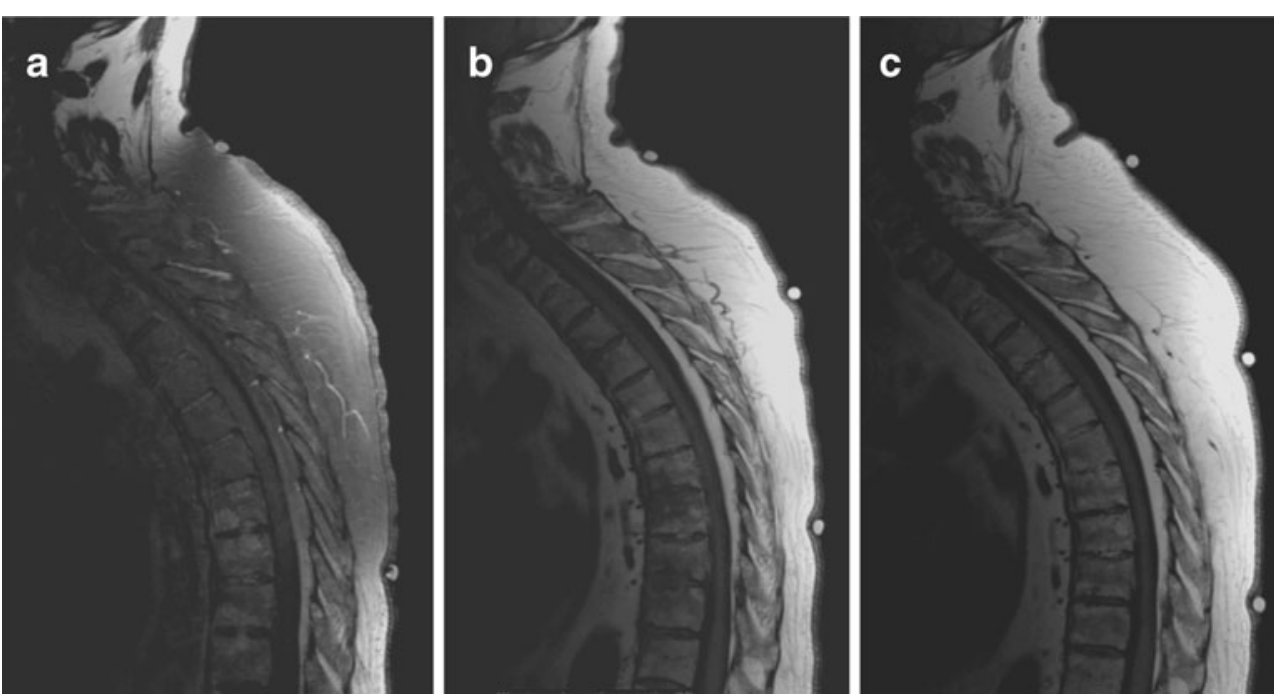

the vertebra, were often detected. These lesions show bone marrow edema in the corners of vertebral endplates and are depicted as hypodense signal areas in T1- and high signal in T2-weighted images [13].

\section{Discussion}

In 56 AS patients, who fulfilled the criteria for treatment with TNF-blocking agents, only one lesion resembling an $\mathrm{AL}$ of the thoracic spine was detected with MRI, but this lesion lacked a fracture line on the conventional radiograph.

The low prevalence of ALs was unexpected because this group of AS patients had a relatively high rate of ankylosis of the spine (24\%) and signs of active inflammation. This was in concordance with the moderate impairment of the mobility of the spine in these patients. The mean tragus-towall distance was $16 \mathrm{~cm}$ (normal, $<15 \mathrm{~cm}$ ), mean lumbar flexion index was $2.5 \mathrm{~cm}$ (normal, $>5 \mathrm{~cm}$ ), the mean lumbar side flexion was $10 \mathrm{~cm}$ (normal, $>10 \mathrm{~cm}$ ), and the mean chest expansion was 3.4 (normal, $>5 \mathrm{~cm}$ ) [14]. The percentage of ALs as described in literature in this subset of severe AS patients varies between $1 \%$ and $28 \%$ [15-21].

Many studies report that the presence of an $\mathrm{AL}$ is associated with long standing disease in AS and with a rigid, ankylosed spine [22-24], concluding that an AL is a late complication of AS [18]. The low prevalence of ALs in our study was probably caused by the relatively short disease duration, with a mean of 11 years and a mean age of 43 years. This could be due to a selection bias, for mostly young patients with an active disease were referred for treatment with TNF-blocking agents, whereas the efficacy of TNF blockers in older and more severe cases of AS with complete ankylosis of the spine was still doubtful at the time of the study.
A severe kyphotic deformity and an osteoporotic spine put a patient at risk of development of a stress fracture in the ankylosed spine $[25,26]$. Our study contains patients with a severe, kyphotic, thoracic spine. However, we did not find any features of stress fractures in this susceptible subgroup of patients, probably due to the small group size.

Another cause of the low prevalence of ALs in this study might be due to the radiographic techniques used to detect them, although the combination of conventional radiographs of the spine and MRI with gadolinium should be sensitive enough. Hermann et al. compared MRI and conventional radiography of spinal changes in patients with spondyloarthritis [22]. They concluded that the best way to detect syndesmophytes was through radiography; ankylosis was detected equally well by both radiography and MRI, but for all other lesions, MRI was the preferred method. A disadvantage of conventional radiographs of the spine is the difficult analysis of the vertebrae of the thoracic segment because of the overimposed lung tissue [27], while most disorders of the discovertebral junction occur in the lower part of the thoracic and upper parts of the lumbar spine [28, 29]. MRI is important for early detection of discovertebral lesions and described as a sensitive method to detect ALs, in particular, after administration of gadolinium [13]. Some MRIs in our study showed features of severe degenerative disk disease (DDD), specifically lumbar-sacral. The MRI features of these degenerative abnormalities were sometimes difficult to distinguish from destructive discovertebral lesions as was described by Jevtic et al., who showed that the appearance of an AL can resemble Modic type III degenerative lesion [13]. One point to differentiate between AL and DDD in AS is the fact that an AL occurs as a result of inflammation in combination with mechanical stress of the ankylosed spine. Another point is that $\mathrm{AL}$ differs from DDD in the localization, because most $\mathrm{AL}$ 
lesions occur at the level of the cervical and thoracolumbar spine, whereas the DDD predominate at the lumbosacral level [7].

The debate about the prevalence of ALs is hampered by the lack of uniformity in the nomenclature of these lesions. For example, the term AL has been employed for severe destructive discovertebral lesions, but also for minor abnormalities such as degenerative changes and local inflammation around in the discovertebral junction, as described in our case [7, 12].

To conclude, no ALs was detected by using conventional radiographs and MRI in this study in 56 severe AS patients, whereas a higher prevalence was described in literature. The discrepancy might be due to the relatively small group of patient with a short disease duration and young age despite the severe ankylosed spine in our study cohort.

Despite the absence of ALs in our study, we would like to increase the awareness of this complication in AS. In case of a minor spine trauma, an MRI should be combined with the conventional spine radiographs in order to detect this lesion in the stiff and vulnerable spine, which is often osteoporotic as well. The treatment of an AL lesion consists of immobilization instead of the routinely advised exercise program or even surgical decompression in case of neurological deficits [7].

In previous studies, there has been no sequential MRI study of the spine in patients with AS that visualizes the evolution from an early discovertebral lesion, as described in our patient, into a severe destructive discovertebral lesion, by some authors called an AL. Thus, it remains unclear whether and how often an abnormality in the discovertebral junction develops into an AL. More research with a long-term follow-up of discovertebral lesions is necessary to clarify the evolution of these lesions.

\section{Disclaimers None.}

\section{Disclosures None.}

Open Access This article is distributed under the terms of the Creative Commons Attribution Noncommercial License which permits any noncommercial use, distribution, and reproduction in any medium, provided the original author(s) and source are credited.

\section{References}

1. Braun J, Bollow M, Remlinger G, Eggens U, Rudwaleit M, Distler A et al (1998) Prevalence of spondylarthropathies in HLAB27 positive and negative blood donors. Arthritis Rheum 41 (1):58-67
2. Braun J, Baraliakos X, Golder W, Brandt J, Rudwaleit M, Listing $J$ et al (2003) Magnetic resonance imaging examinations of the spine in patients with ankylosing spondylitis, before and after successful therapy with infliximab: evaluation of a new scoring system. Arthritis Rheum 48(4):1126-1136

3. Maksymowych WP, Landewe R (2006) Imaging in ankylosing spondylitis. Best Pract Res Clin Rheumatol 20(3):507-519

4. Marc V, Dromer C, Le GP, Manelfe C, Fournie B (1997) Magnetic resonance imaging and axial involvement in spondylarthropathies. Delineation of the spinal entheses. Rev Rhum Engl Ed 64(7-9):465-473

5. van der Heijde D, Landewe R (2005) Imaging in spondylitis. Curr Opin Rheumatol 17(4):413-417

6. Andersson O (1937) Röntgenbilden vid spondylarthritis ankylopoetica. Nord Med Tidskr 14:2000-2002

7. Bron JL, de Vries MK, Snieders MN, van der Horst-Bruinsma IE, Van Royen BJ (2009) Discovertebral (Andersson) lesions of the spine in ankylosing spondylitis revisited. Clin Rheumatol 28 (8):883-892

8. Rasker JJ, Prevo RL, Lanting PJ (1996) Spondylodiscitis in ankylosing spondylitis, inflammation or trauma? A description of six cases. Scand J Rheumatol 25(1):52-57

9. Braun J, Pham T, Sieper J, Davis J, van der Linden S, Dougados $M$ et al (2003) International ASAS consensus statement for the use of anti-tumour necrosis factor agents in patients with ankylosing spondylitis. Ann Rheum Dis 62 (9):817-824

10. Braun J, Davis J, Dougados M, Sieper J, van der Linden S, van der Heijde D (2006) First update of the international ASAS consensus statement for the use of anti-TNF agents in patients with ankylosing spondylitis. Ann Rheum Dis 65 (3):316-320

11. Garrett S, Jenkinson T, Kennedy LG, Whitelock H, Gaisford P, Calin A (1994) A new approach to defining disease status in ankylosing spondylitis: the bath ankylosing spondylitis disease activity index. J Rheumatol 21(12):2286-2291

12. Van Royen BJ, Kastelijns RC, Noske DP, Oner FC, Smit TH (2006) Transpedicular wedge resection osteotomy for the treatment of a kyphotic Andersson lesion-complicating ankylosing spondylitis. Eur Spine J 15(2):246-252

13. Jevtic V, Kos-Golja M, Rozman B, McCall I (2000) Marginal erosive discovertebral "Romanus" lesions in ankylosing spondylitis demonstrated by contrast enhanced Gd-DTPA magnetic resonance imaging. Skeletal Radiol 29(1):27-33

14. Wanders A, Landewe R, Dougados M, Mielants $H$, van der Linden S, van der Heijdi D (2005) Association between radiographic damage of the spine and spinal mobility for individual patients with ankylosing spondylitis: can assessment of spinal mobility be a proxy for radiographic evaluation? Ann Rheum Dis 64(7):988-994

15. Cawley MID, Chalmers TM, Ball J, Kellgren JH (1972) Destructive lesions of vertebral bodies in ankylosing-spondylitis. Ann Rheum Dis 31(5):345-358

16. Guma M, Olive A, Perez R, Holgado S, Ortiz-Santamaria V, Tena X (2001) Aseptic spondylodiskitis in rheumatic diseases. Clin Exp Rheumatol 19(6):740-747

17. Hehne HJ, Becker HJ, Zielke K (1990) The spondylodiscitis in kyphotic deformities of ankylosing spondylitis and the influence of dorsal correction osteotomies. Report on 33 patients. Z Orthop Ihre Grenzgeb 128(5):494-502

18. Kabasakal Y, Garrett SL, Calin A (1996) The epidemiology of spondylodiscitis in ankylosing spondylitis - a controlled study. $\mathrm{Br}$ J Rheumatol 35(7):660-663

19. Langlois S, Cedoz JP, Lohse A, Toussirot E, Wendling D (2005) Aseptic discitis in patients with ankylosing spondylitis: a retrospective study of 14 cases. Joint Bone Spine 72(3):248-253 
20. Lanting PJ, Rasker JJ, Kruijsen MW, Prevo RL (1994) Spondylodiscitis in Bechterew's disease; inflammation or trauma? Description of 6 patients. Ned Tijdschr Geneeskd 138(40):19972001

21. Tsuchiya K, Nagamine R, Iwamoto Y (2002) Discovertebral lesion in ankylosing spondylitis: differential diagnosis with discitis by magnetic resonance imaging. Mod Rheumatol 12(2):113-117

22. Hermann KGA, Althoff CE, Schneider U, Zuhlsdorf SZ, Lembcke A, Hamm B et al (2005) Spinal changes in patients with spondyloarthritis: comparison of MR imaging and radiographic appearances. Radiographics 25(3):559-569

23. Obradov M, Schonfeld DH, Franssen MJ, de Rooy DJ (2001) Andersson lesion in ankylosing spondylitis. JBR-BTR 84(2):71

24. Yau ACMC, Chan RNW (1974) Stress fracture of fused lumbodorsal spine in ankylosing-spondylitis. J Bone Jt Surg-Br Vol B 56 (4):681-687

25. Cooper C, Carbone L, Michet CJ, Atkinson EJ, O'Fallon WM, Melton LJ III (1994) Fracture risk in patients with ankylosing spondylitis: a population based study. J Rheumatol 21(10):18771882

26. Maillefert JF, Aho LS, El MA, Dougados M, Roux C (2001) Changes in bone density in patients with ankylosing spondylitis: a two-year follow-up study. Osteoporos Int 12(7):605-609

27. Braun J, Baraliakos X, Golder W, Hermann KG, Listing J, Brandt $J$ et al (2004) Analysing chronic spinal changes in ankylosing spondylitis: a systematic comparison of conventional $\mathrm{x}$ rays with magnetic resonance imaging using established and new scoring systems. Ann Rheum Dis 63(9):1046-1055

28. Baraliakos X, Landewe R, Hermann KG, Listing J, Golder W, Brandt $J$ et al (2005) Inflammation in ankylosing spondylitis: a systematic description of the extent and frequency of acute spinal changes using magnetic resonance imaging. Ann Rheum Dis 64 (5):730-734

29. Braun J, Golder W, Bollow M, Sieper J, van der Heijde D (2002) Imaging and scoring in ankylosing spondylitis. Clin Exp Rheumatol 20(6 Suppl 28):S178-S184 